UC-15

lssued: February 1987

\title{
Liquid Sample Shuffler for Gannma Active Solutions
}

LA- -10925-MS

T. W. Crane

DE87 004774

\section{DISCLAIMER}

This report was prepared as an account of work sponsored by an agency of the Uniter States Government. Neither the United States Government nor any agency thereof, nor any of their employees, makes arly warranty, express or implied, oz assumes any legal liability or responsibility for the accuracy, completeness, or usefulness of any information, apparatus, product, or process disclosed, or represents that its use would not infringe privately owned rights. Reference herein to any specific commercial .roduct, process, or service by trade name, trademark, manufacturer, or otherwise does not necessarily constitute or imply its endorsement, recommendation, or favoring by the United States Government or any agency thereof. The views and opinions of authors expressed herein do not necessarily state or reflect those of the United States Government or any agency thereof. 
CONTENTS

ABSTRACT .. . . . . . . . . . . . . . . . . 1

I. INTRODUCTION . . . . . . . . . . . . . . 2

II. CONCEPT . . . . . . . . . . . . . . . . . . 2

III. PHOTON RADIATION DOSE . . . . . . . . . . . . . 5

IV. NEUTRON RADIATION DOSE . . . . . . . . . . . . . 7

v. DESIGN COMPARISONS .. . . . . . . . . . . . 11

VI. RECOMMENDATIONS . . . . . . . . . . . . . . 12

ACKNOULEDGMENTS . . . . . . . . . . . . . . . . . . 14

REFERENCES • . . . . . . . . . . . . . . . . 15 


\section{LIQUID SAMPLE SHUFFLER FOR GAMMA ACTIVE SOLUTIONS}

by

T. W. Crane

\section{ABSTRACT}

An instrument is proposed by Los Alamos National Laboratory for measuring low levels of fission-product-contaminated fissile solutions at the Idaho National Engineering Laboratory (INEL). The proposed unit uses neutrons from a ${ }^{252} \mathrm{CE}$ neutron source to induce fissions, and delayed neutrons from the incuced fisstons are counted once the neutron source is withdrawn. Lead is used to shield the neutron detectors from the gama-ray dose of the fission products found in the solutions at the INEL plant. The designed sensitivity is $5 \mathrm{mg} / \mathrm{l}$ of $235 \mathrm{U}$ in $100 \mathrm{~s}$ with a 4-standard-deviation confidence. 


\section{INTRODUCTION}

Liquid waste streams in the uranium recovery facllity are to be measured at the Idaho National Engineering Laboratory (INEL), with the goal of detecting concentrations a.s low as $5 \mathrm{mg} / \mathrm{l}$ of ${ }^{235} \mathrm{U}$ in $100 \mathrm{~s}$ with a 4-standard-deviation confidence. Because the solutions are part of a separations process, irradiation doses as high as $50 \mathrm{R} / \mathrm{h} / \mathrm{l}$ may accompany the urantum. A measurement scheme is recommended that will detect the ${ }^{235} \mathrm{U}$ and tolerate the radiation dose.

\section{CONCEPT}

Several measurement systems were considered by INEL and LOS Alamos National Laboratory. The low-uranium concentrations, radiation from fission products, or possible component degradation in the process line were serious obstacles for each system considered. Reviewers of the varlous choices thought that the ${ }^{252}$ Cf shuffler measurement apparatus could meet the requirements. The proposed measurement instrument had been tested at Los Alamos, ${ }^{1}$ and duplicates of the components used in the nondestructive assay (NDA) instruments had seen in-plant service. ${ }^{2-3}$

The NDA apparatus uses a ${ }^{252}$ Cf neutron source to induce fisstons, and the instrument counts delayed neutrons after the neutron source is withdrawn. About $10 \mathrm{~s}$ are used for neutron irradiation, and $10 \mathrm{~s}$ are used for delayedneutron counting. Figure 1 depicts the cyclic assay sequence. The active cycle of irradiation and delayed-neutron counting is repeated to build up a statistically significant number of counts. A background count precedes the active portion of the assay and uses about one-third of the assay time.

The feature of the Liquid sample shuffler that leads to its enhanced sensitivity over other ${ }^{252} \mathrm{CE}$ assay systems is that the neutron source is transferred to the center of the solution tank through a source insertion port (see Fig. 2). From this centralized location, nearly every neutron emitted has a chance to induce a fission. The fission process is further enhanced because the hydrogenous nature of solutions and polyethylene increases the thermal neutron component during irradiation. 4 Low-energy thermal neutrons have a much larger cross section for inducing a fission than high-energy neutrons directly 

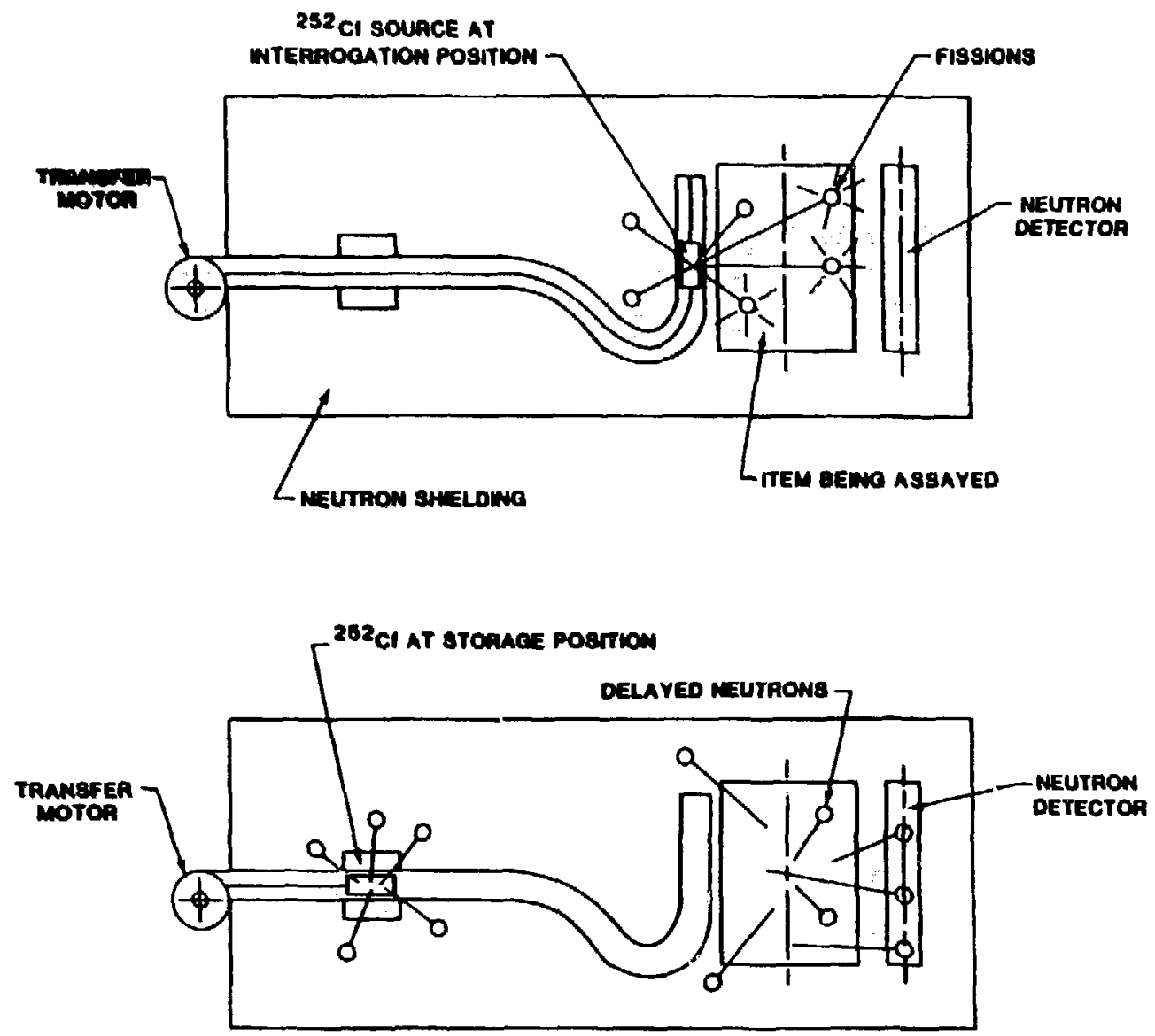

Fig. 1. Shuffler measurement sequence. Top view: ${ }^{252} \mathrm{Cf}$ isotopic neutron source is used to induce fissions. Botton view: delayed neutrons are counted once the ${ }^{252} \mathrm{Cf}$ source is withdrawn. (EG\&G Neg. No. 10315)

from the californium source. The detection efficiency for delayed neutrons remains high because features used in coincidence well counters can be applied to the Liquid sample shuffler assay tank. The intrinsic background neutron count rate is low with this type of system, because the system uses only a few relatively short neutron detectors that can be well shielded from the source and other external background radiation.

The solution volume is set at $1.8 \ell$ to meet INEL criticality safety requirements. The absolute minimum critical volume is 3.6 \& for ${ }^{233} \mathrm{U}^{5}$ Actually, the instrument provides additional criticality safety features beyond the small 1.8- $\ell$ volume. First, the shape of the active volume is favorable because of the annular construction; second, the neutron detectors absorb neutrons; and third, ${ }^{233} \mathrm{U}$ is not measured in the NDA instrument. The minimum 
1 Uranyl Nitrate

2 Polyethylene

3 Lead

4 Steel

5 Cadmium

6 Aluminum

7 Copper

8 Helium-3
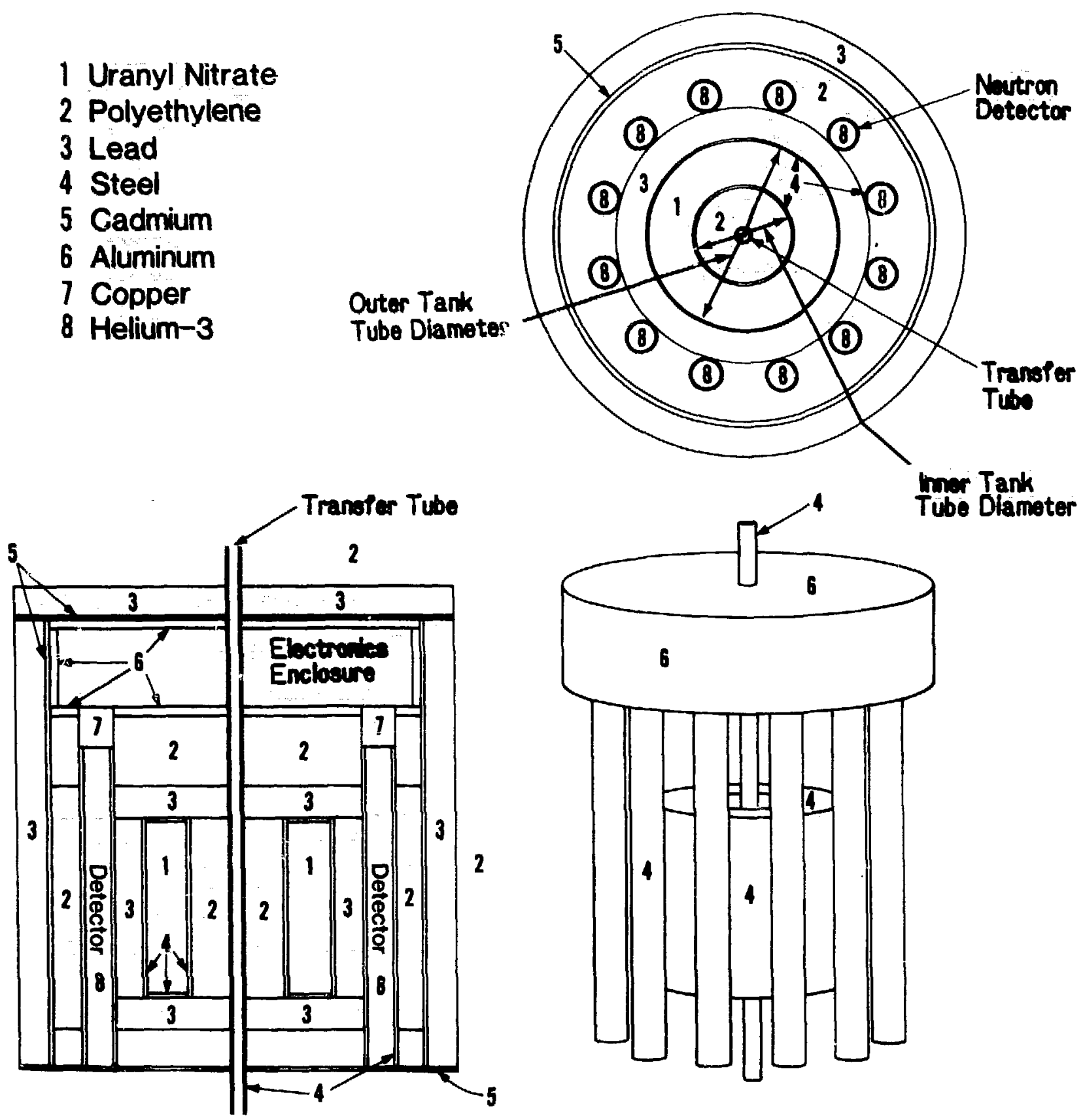

Fig. 2. Favored geometry for a $1.8-\ell$ Liquid sample shuffler assay tank. (EG\&G Neg. No. 10924R) 
volumes for aqueous nitrate solutions of ${ }^{235} \mathrm{U}$ and ${ }^{239} \mathrm{Pu}$ are over $6 \ell$. Both ${ }^{235} \mathrm{U}$ and ${ }^{239} \mathrm{Pu}$ are present at the facility. Because the tank is smaller than the minimum critical volume for either of these two isotopes by at least a factor of 3 , the tank is safe.

III. PHOTON RADIATION DOSE

The Idaho Chemical processing Plant solutions to be measured contain fission products. These gamma-ray emitters make the solutions radioactive to the point of being a health hazard if no personnel shielding was provided. The photon spectrum provided by INEL is given in Table $I$. This spectrum is used to determine the shielding properties of lead between the solution and the gasfilled neutron detectors. The actual photon emission rate may be higher or lower than the dose rate given in Table $I$. However, the lead shielding property is determined by the spectrum given in Table $I$.

The photon emission rate described in Table I yields a dose rate to the neutron detectors of less than $5 \mathrm{R} / \mathrm{h}$ as calculated at INEL and Los Alamos. This dose rate on an 8-in. gas-filled neutron detector is acceptable with no adverse effects on the expected count rate if separate electronic chains are

\section{TABLE I}

PHOTON EMISSION SPECTRUM FOR FISSION PRODUCTS IN SOLUTIONS TO BE MEASURED AT INEL

Photon Energy

(MeV)

0.085

0.150

0.475

0.65

1.00

1.225

1.475

2.30
Emission Rate (photons/s/l)

$5.49 \times 10^{5}$

$3.65 \times 10^{6}$

$4.12 \times 10^{8}$

$2.31 \times 10^{8}$

$2.92 \times 10^{7}$

$9.71 \times 10^{6}$

$3.89 \times 10^{6}$

$1.95 \times 10^{6}$ 
used for each detector. However, a more conservative tack to avold photon interference is recommended. This approach is to add lead between the solution and detectors. Negative effects, none serious, to this approach are:

(1) the neutron detectors are further from the solution so that neutron detection efficiency is lower.

(2) the inner ring of detectors must be omitted because of space restrictions, and

(3) the presence of lead increases the neutron background from cosmic-ray interactions. 6

For estimating an upper bound of this cosmic-ray-induced background rate, lead bricks were placed in a High-Level Neutron Colncidence Counter (HLNCC) ${ }^{7}$ and the cosmic-ray-induced neutron rate was measured. From the data taken with this test (see Table II), an induced count rate of $0.0861 \pm 0.0005$ counts $/ \mathrm{s} / \mathrm{kg}$ is observed at the Los Alamos altitude of $2200 \mathrm{~m}$. The rate at INEL would be decreased because of INEL's lower elevation and because of the thick concrete walls planned for the facility. The count rates measured in the HLNCC are similar to those expected in the Liquid Sample Shuffler because the neutron detection efficiencies are comparable.

For estimating the cosmic-ray-induced neutron flux at the planned INEL facility, a well counter (HLNCC), associated electronics, and lead bricks could be supplied by Los Alamos. Measurement of the cosmic-ray background would answer questions concerning altitude and latitude as well as construction materials. Questions associated with construction materlals are: (1) how much

TABLE II

BACKGROUND NEUTRON RATES MEASURED IN AN HLNCC AT LOS ALAMOS

\begin{tabular}{|c|c|c|c|c|}
\hline Configuration & $\begin{array}{l}\text { Time } \\
\text { (s) }\end{array}$ & Totals & Coincidences & Accidentals \\
\hline Empty chamber & 80000 & 1262742 & 3665 & 601 \\
\hline One lead brick ( $11.90 \mathrm{~kg})$ & 80000 & 1345669 & 29168 & 668 \\
\hline Two lead bricks $(23.81 \mathrm{~kg})$ & 80000 & 1445160 & $63 \quad 474$ & 832 \\
\hline Three lead bricks $(35.71 \mathrm{~kg})$ & $80 \quad 000$ & 1495998 & 105385 & 840 \\
\hline
\end{tabular}


overhead cosmic-ray shielding is incorporated into the building, and (2) what percentage of background can be attributed to construction materials?

Because none of the drawbacks to adding lead shielding between the solution and detectors (or between the solution and electronics to reduce the accumulated dose on the electronics) appeared to be insurmountable, Monte carlo neutron transport calculations ${ }^{8}$ were completed. Monte carlo is a name given to the neutron and photon computer codes where a particle is tracked and outcomes of possible interactions such as scattering, absorption, or inducing a fission are determined randomly based on the known probability for each interaction. A large number of particles are tracked to reduce fluctuation of the result. The final result is accurate to within the statistical limits of the caiculation. For example, Monte carlo calculations accurate to $3 \%$ anticipated calibration data obtained with an instrument about a year later. 2

For the first Monte Carlo runs, designs without lead shielding were tried (see sec. V). Then, lead shielding was added around the tank to shield the neutron detectors. Preliminary calculations showed the effectiveness of lead shielding in reducing gamma-ray rates (see Table III). Lead was added in $1 / 2$-in. increments to evaluate its effectiveness for the photon spectrum expected. One-half-inch sheets are standard sizes, but the lead could be cast in any desired shape and thickness. From inspection of the results, a 1-in. thickness appears to be the most practical. This amount of lead reduced a $25-\mathrm{R} / \mathrm{h}$ field to about $\mathrm{l} \mathrm{R} / \mathrm{h}$.

The estimates given in Table III are conservative because the calculation assimed that photons entered normal to the lead surface, yielding a minimum path length in the lead. An additional radiation reduction factor is present because the extra space needed to accommodate the lead shield is not Included in the dose estimation. This extra distance will make the dose experienced by the detectors less. Thus, the lead thickness estimated in the calculational model will be more effective than quoted.

IV. NEUTRON RADIATION DOSE

With spent fuel, neutron doses also accompany the photon doses. The particular isotopes of interest for neutron emission are the even isotopes of 


\section{LEAD SHIELDING PROPERTIES FOR THE GAMMA-RAY SPECTRUM} GIVEN IN TABLE I

\begin{tabular}{cl}
$\begin{array}{c}\text { Lead Thickness } \\
\text { (cm) }\end{array}$ & Transmission \\
\hline 0.00 & 1.0000 \\
1.27 & $0.1820 \pm 0.0003$ \\
2.54 & $0.0528 \pm 0.0008$ \\
3.81 & $0.0178 \pm 0.0007$ \\
5.08 & $0.0070 \pm 0.0005$
\end{tabular}

plutonium and curium. These elements would partition with the fission products. If created, they could be seen in the waste streams.

Because the uranium is initially highly enriched in ${ }^{235} \mathrm{U}$, plutonium and curium, which begin their production with neutron capture on ${ }^{238} U$, are minimized. The even isotopes of plutonium and curium fission spontaneously and this neutron background results in a need to increase the size of the californium source. Plutonium and curfum content in the INEL waste is known to be small, but the exact value is not known. The neutron background from these isotcpes can be measured once the plant begins full operation. If necessary, the source size can be increased (slightly) to compensate for the neutron background. Because the amount of these isotopes is small, the projected increment in the californium source size is also small.

The even isotopes of plutonium and curium could be monitored by passive neutron counting during the background-counting portion of the assay. The actual neutron emission levels could be used to determine if singles counting or coincidence counting gives a better measurement of the quantity of plutonium and curium in the solution.

The following five sources contribute to the background:

(1) intrinsic detector background,

(2) the ${ }^{252} \mathrm{CE}$ interrogation source,

(3) cosmic-ray interactions,

(4) the item being measured, and

(5) neutron-emitting materials at the facility. 
Backgrounds vary with the facility where the measurements are performed. Sources (3), (4), and (5) are closely tied to this effect. The background from source (2) can be reduced by increasing the separation between the source storage position and assay chamber. This distance is usually limited by the avallable space at the Eacility. The intrinsic background source, ( 1 ), has been measured only at Los Alamos, so facility-related effects cannot be ruled out. However, the observed rate is small compared to other effects. Table IV estimates the background to be expected for the proposed Liquid Sample shuffler at INEL. Equation (1) calculates the number of delayed neutron counts needed to reach the desired precision, 4 standard deviations. Equation (2) gives the count rate for delayed neutrons per microgram of ${ }^{252} \mathrm{Cf}$; the fission-inducing, delayed-neutron counting, and background characteristics of tank 5 in Table V are used.

The solution gamma-ray contribution to the observed background is estimated from the data included in Ref. 9. The contribution from the neutron emitters in solution is small and not known, so no entry is included from this background source. The number of neutron counts needed to reach a given precision is

$$
c=\left[d^{2}+\left(d^{4}+8 B d^{2}\right)^{1 / 2}\right] / 2
$$

where $d$ = desired standard deviations above background $(d=4)$, and

$B=$ background counts during the measurement (30-s count time).

The delayed-neutron signal from the solution for tank 5 in Table $\mathrm{V}$ is given by:

$3.58 \times 10^{-5}$ fission/source neutron with a 5-mg/l solution

$$
\begin{aligned}
& \text { x } 0.0167 \text { delayed neutron/fission } \\
& x \quad 0.23 \text { countable neutron/delayed neutron } \\
& x 0.221 \text { counts/countable neutron } \\
& \text { x } 2.33 \times 10^{6} \text { source neutrons/s/ug } 252 \mathrm{Cf} \\
& =0.0709 \text { counts } / \mathrm{s} / \mu \mathrm{g}^{252} \mathrm{Cf} .
\end{aligned}
$$


INTERRCGATING ${ }^{252} \mathrm{CF}$ SOURCE SIZE UITH ESTIMATED BACKGROUND RATE NEEDED TO REACH THE DESIGN SENSITIVITYa

\begin{tabular}{|c|c|c|c|}
\hline \multirow[b]{2}{*}{ Neutron Backqround Type } & \multicolumn{2}{|c|}{$\begin{array}{l}\text { Background } \\
\text { (counts/s) }\end{array}$} & \multirow{2}{*}{$\begin{array}{c}{ }^{252} \mathrm{cf} \\
\text { Source size } \\
(\mu q) \\
\end{array}$} \\
\hline & Incremental & Total & \\
\hline No background & 0.0 & $\therefore 0$ & 7.5 \\
\hline Intrinsic & 0.4 & 0.4 & 13.7 \\
\hline $\begin{array}{l}252 \text { CE neutron sourceb } \\
\text { (4-ft separation) }\end{array}$ & 0.2 & 0.5 & $\therefore .7$ \\
\hline $\begin{array}{l}\text { Cosmic-ray interactions in lead } \\
\text { (Los Alamos elevation) }\end{array}$ & 3.6 & 4.1 & 32.9 \\
\hline Solution ganma rays & $>0.1$ & 4.1 & 32.9 \\
\hline $\begin{array}{l}\text { Solution neutron emitters (even } \\
\text { plutonium and curium isotopes) }\end{array}$ & 0.0 & --- & -- \\
\hline $\begin{array}{l}\text { a5-mg/l of }{ }^{235} \mathrm{u}, 4 \text { standard dev } \\
\text { biveutron shlelding effectivenes } \\
\text { viewed Erom the source storage } \\
\text { ethylene, ( } 3 \text { ) factor of } 4 \text { for } \\
\text { efflclency has neutrons emitte }\end{array}$ & $\begin{array}{l}\text { ns, in } 100 \mathrm{~s} \\
\text { 1) solid ang } \\
\text { tion, ( } 2 \text { ) fa } \\
\text { um sheet, an } \\
\text { the solution }\end{array}$ & $\begin{array}{l}\text { ubtend } \\
\text { of } 2 \\
\text { sane } \\
\text { t. }\end{array}$ & $\begin{array}{l}\text { detectors } \\
\text { of poly- } \\
\text { detection }\end{array}$ \\
\hline
\end{tabular}

TABLE V

DESIGN CHARACTERISTICS FOR SIX LIQUID SAMPLE SHUFFLERS

\begin{tabular}{|c|c|c|c|c|c|c|c|}
\hline Tank & $\begin{array}{c}\text { Inner Tube } \\
\text { Diameter } \\
\text { (in.) }\end{array}$ & $\begin{array}{l}\text { Outer Tube } \\
\text { Dianeter } \\
(\text { in. })\end{array}$ & $\begin{array}{l}\text { Helght } \\
\text { (in.) }\end{array}$ & $\begin{array}{l}\text { Number of } \\
\text { Detectors }\end{array}$ & $\begin{array}{l}\text { Background } \\
\text { (counts/s) }^{b}\end{array}$ & $\begin{array}{c}\text { Interrogation }{ }^{c} \\
\text { Efficlency } \\
(\mathrm{f} / \mathrm{sn})^{\mathrm{d}} \\
\end{array}$ & $\begin{array}{l}\text { Detection } \\
\text { Efficiency } \\
(8)\end{array}$ \\
\hline 1 & 3.5 & 6.0 & 6.281 & 13 & 0.433 & $5.23 \times 10^{-5}$ & 32.4 \\
\hline 2 & 4.0 & 6.0 & 7.553 & 15 & 0.500 & $3.31 \times 10^{-5}$ & 34.7 \\
\hline 3 & 3.5 & 7.0 & 3.994 & 15 & 0.500 & $6.16 \times 10^{-5}$ & 31.7 \\
\hline 4 & 4.0 & 7.0 & 4.473 & 17 & 0.567 & $4.52 \times 10^{-5}$ & 38.4 \\
\hline 5 & 3.0 & 6.0 & 5.481 & 12 & 3.940 & $7.17 \times 10^{-5}$ & 22.1 \\
\hline 6 & 3.5 & 7.0 & 3.994 & 14 & 4.112 & $6.46 \times 10^{-5}$ & 25.6 \\
\hline
\end{tabular}

\footnotetext{
atube wall thickness $=1 / 16$ in.

birectly scaled by total detector length from the prototype Liquid sample shuffler unit with a measured background rate of 0.1 counts/s with $5 i x$ 4-in. detectors. Counts assoclated with lead shlelding are added to the background rate. Csolution concentration of $10 \mathrm{mg} 235 \mathrm{u} / \mathrm{l}$.

$\mathrm{d}_{\mathrm{f} / \mathrm{sn}}=\mathrm{E} 1 \mathrm{ss}$ ions per source neutron.
} 
Ir: a 30-s measurement, we estimate 2.1 counts/ug of ${ }^{252} \mathrm{Cf}$ for the fifth entry in Table V. Table IV contains the background estimate for several background contributors. The source sizes needed to meet the detectability limit given in Table VI were computed with help from Eqs. (1) and (2).

\section{DESIGN COMPARISONS}

Several Monte Carlo $0^{8}$ results are listed in Table V. The first four designs listed have no lead shielding and both an inner and outer ring of ${ }^{3} \mathrm{He}-$ filled neutron detectors. The 8-in. detectors can operate in a photon radiation field of up to $6 \mathrm{R} / \mathrm{h}$ with no deterforation in performance at the expected count rate if each detector has sole use of the amplifier electronics. The ability to distinguish between neutrons and photons is completely lost at fields of about $20 \mathrm{R} / \mathrm{h}$ for a $4-\mathrm{ft}$ detector. ${ }^{9}$

The last two systeins listed in Table $V$ (entrias 5 and 6 ) have a 1-in.thick lead shield between the solution tank and detectors. The 1-in.-thick

\section{TABLE VI}

CALIFORNIUM-252 SOURCE SIZE NEEDED

TO MEET THE DETECTARILITY LIMIT ${ }^{a}$

FOR THE SOLUTION TANKS LISTED IN TABLE V

$\underline{\text { Tank }}$

1

2

3

4

5

6

\section{Source Size \\ (ug)}

13.2

20.3

11.9

14.0

32.9

32.1

as $\mathrm{mg} / \mathrm{l}$ of $235 \mathrm{U}, 4$ standard deviations, in $100 \mathrm{~s}$. 
lead shield would reduce a $50-\mathrm{R} / \mathrm{h}$ gamma-ray field to less than $2.6 \mathrm{R} / \mathrm{h}$. The lead shield mass is $41.12 \mathrm{~kg}$ for the fifth entry and $42.33 \mathrm{~kg}$ for the sixth entry. The fifth system, the one with the 3-in.-diam inner stainless steel tube for the tank wall, has the most convenient dimensiors for construction. All the designs listed in Table $V$ attempted to use available standard sizes. Any of the systems can accommodate spray jets to ease cleanout. The tank geometry used for the fifth entry is shown in Fig. 2.

The source size that meets the detectability limit (5 mg/, 4 standarc. deviations, in $100 \mathrm{~s}$ ) is listed in Table VI for each design given in Table V. A report on calculating detectability limits is given in Ref. 10. The order of the solution chambers given in Table $\mathrm{V}$ is followed in Table VI.

Table VII estimates personnel radiation exposure at the surface of the shuffler. Transmission of solution gamma rays is given in Table III. The shielding is inadequate on the sides of the proposed instrument for personnel exposure protection, and additional polyethylene and lead shielding must be used on the outer ends of a series of instruments. Three instruments are shown in the drawing of installed instruments in Fig. 3.

\section{RECOMMENDATIONS}

The tank shown in Fig. 2 (tank 5 in Tables $V$ and $V I$ ) is recommended for the application at INEL. Figure 2 was produced with the aid of both the twoand three-dimensional modeling features of the Los Alamos Monte Carlo code. 8

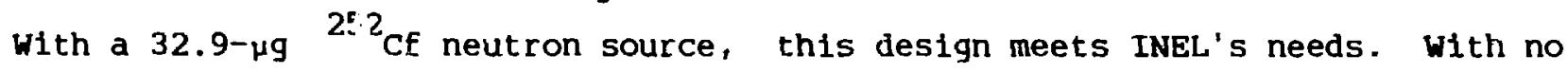
cosmic-ray-induced neutron background radiation, a source possibly only one-half as large will suffice. The use of lead shielding assures that the neutron detectors will be able to tolerate the estimated solution photon dose cate. To meet the exterior dose rate; only the design with the source biased 4 in. to the rear (see Table VII) qualifies. With the source positioned toward the rear, the back surface no longer meets the dose restriction and personnel access must be blocked to prevent exposure.

For 2-1/2 yr of operation, the californium source used must be twice as large as its end-of-life size to allow for decay during its first half-life. Neutron detectors can be added to the storage position to record the natural 
TABLE VII

FERSONNEL RADIATION EXPOSURE

FOR SOLUTION-MEASURING SHUFFLERS ${ }^{a}$

Configuration

Solution $\quad 252 \mathrm{Cf}$

Radiation Dose (mR/h)

Centered tank ${ }^{c}$

Front surface

0.0007

0.4

2.5

0.8

3.7

Back surface

0.12

4.0

2.5

8.0

14.6

Tank 4 in. back

Front surface

$0.00009 \quad 0.2$

0.5

0.35

1.0

Back surface

0.007

8.5

16.0

17.0

41.5

axterior dose in $\mathrm{mR} / \mathrm{h}$ and a generic configuration are assumed: (1) a solution of $50 \mathrm{R} / \mathrm{h}$ and a $50-\mu \mathrm{g}{ }^{252} \mathrm{Cf}$ neutron source, (2) a 2-in.-thick lead shield, (3) polyethylene, and (4) an outer layer of 2-in.-thick lead.

bedth $=36$ in.; width $=26$ in.

centered front to back; same dose as storage.

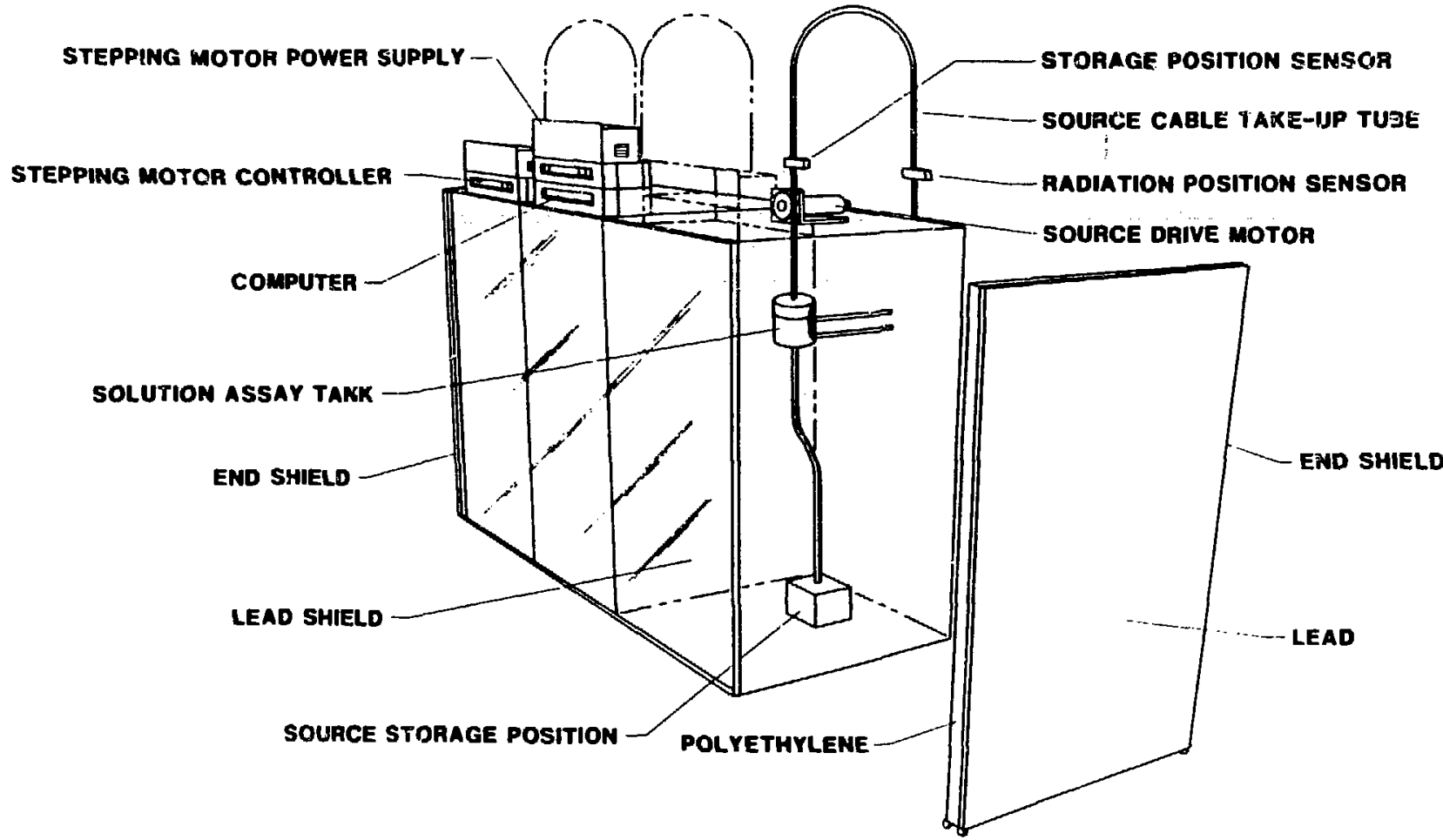

Fig. 3. Schematic representation of three Liquid Sample shufflers in simultaneous use. (EG\&G Neg. No. 10963) 
decay. If longer count times are avallable or less sensitivity is needed, the strength of the californium source can be reduced.

If a weak photon radiation field is present in the solution, a design with no lead shielding surrounding the tank, like the first design listed in Table $V$, may be used. This design gains in delayed-neutron detection efficiency and has a lower background rate; however, it has a lower induced fission rate because, presumably, Eewer source neutrons are scattered back into the solution tank. Nonetheless, an ovel:all gain is made and the proposed NDA instrument needs about a $13-\mu \mathrm{g}{ }^{252} \mathrm{CE}$ source to make the $5-\mathrm{mg} / \mathrm{l}{ }^{235} \mathrm{U}$ sensitivity in $100 \mathrm{~s}$. The enhanced sensitivity is mostly due to the addition of two detectors in the center section. The lack of lead shielding will reduce the backigound, and the extra detectors improve the passive counting efficiency.

Measurement of low-level waste has been the emphasis of this report. of course, the system will also measure product streams. The uniformity of solutions and the relatively short neutron path length across the tank minimize self-shielding effects. Also, multiplication serves to cancel self-shielding. The danger in an increase in multiplication is that the system is brought closer to being critical. In the Monte Carlo simulation described in Ref. 1 , the size and shape of the tank were adjusted to make multiplication override self-shielding. With a properly chosen tank, a linear behavior can be achleved and the tank can st 11 be kept from being critical.

\section{ACKNOWLEDGMINTS}

I would like to thank T. C. Piper, INEL, for relaying information on the needs and restrictions of INEL, and the following Los Alamos personrel for technical support: P. R. Collinsworth, for assistance in preparing the test bed system for the preliminary measurements; M. C. Tinkle, for preparing the uranium solution used in the test bed measurements; H. O. Menlove, for contributing data on detector and electronics gamma-ray susceptibility; and $G$. $W$. Eccleston, for providing useful comments on this report and on the design of the proposed instrument. I also thank 5 . Kreiner for editorial comments. 


\section{REFERENCES}

1. T. W. Crane, "Liquid Sample Shuffler," Los Alamos National Laboratory report LA-10291-MS (January 1985).

2. T. W. Crane, "Test and Evaluation Results of the ${ }^{252} \mathrm{Cf}$ Shuffler at the Savannah River Plant," Los Alamos National Laboratory report LA-8755-MS (March 1981).

3. G. W. Eccleston, B. Stuewe, S. Kloste -buer, and T. Van Lyssel, "Dounreay shuffler Diagnostic Software Operations Manual," Los Alamos National Laboratory report LA-10470-M (July 1985).

4. T. H. Crane and P. R. Collinsworth, "Fissile Solution Measurement Apparatus," Us Patent Application, May 1984.

5. "Safety in Conducting Neutron-Multiplication Measurements In Situ," American National Standards Institute report 8.6 (1983).

6. A. R. 'Tobey and C. G. Montgomery, "Neutron Production by Cosmic Rays at Sea Level," Phys. Rev. 81, (4), 517-519 (February 15, 1951).

7. M. S. Krick and H. O. Menlove, "The High-Level Neutron Coincidence Counter (HLNCC): Users" Manual," Los Alamos Sclentiflc Laboratory report LA-7779-M (ISPO-53) (June 1979).

8. Los Alamos Monte Carlo Code Group, "MCNP--A General Monte Carlo Code for Neutron and Photon Transport, Version 3," Los Alamos National Laboratory report LA-7396-M, Rev. (April 1981). Additional : evisions are available from Los Alamos Group X-6.

9. T. W. Crane, "Gas Mixture Evaluation for ${ }^{3}$ He Neutron Detectors," in "Nuclear Safeguards Research and Development Program stetus Report May-August 1977." J. L. Saplr, Ed., Los Alamos Scientific Labcratory report LA-703G-PR (Maich 1978), Pp. 39-40,

10. T. W. Crane, "Detectability Limits and Frecision for shufflers," Los Alamos National Laboratory report LA-10158-MS (August 1984). 